\title{
Make visible the invisible: Optimized development of an environmental DNA metabarcoding tool for the characterization of trematode parasitic communities
}

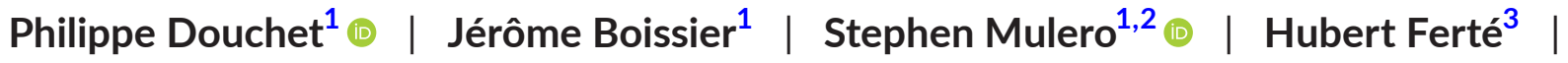 \\ Margot Doberva $^{4}$ | Jean-François Allienne ${ }^{1}$ | Eve Toulza ${ }^{1}$ | Kévin Bethune ${ }^{5}$ | \\ Olivier Rey ${ }^{1}$
}

${ }^{1}$ IHPE, Univ Montpellier, CNRS, IFREMER, Univ Perpignan Via Domitia, Montpellier, France

${ }^{2}$ Laboratoire d'Ecologie Alpine, UMR UGA-USMB-CNRS 5553), Université Grenoble-Alpes, Grenoble, France

${ }^{3}$ EA 7510, ESCAPE, Laboratoire de Parasitologie-Mycologie, Université de Reims Champagne-Ardenne, Reims, France

${ }^{4}$ Plateforme technologique BioEnvironnement, Université de Perpignan Via Domitia, Perpignan, France

${ }^{5}$ CEFE, CNRS, Montpellier, France

\section{Correspondence}

Olivier Rey and Philippe Douchet, IHPE, Univ Montpellier, CNRS, IFREMER, Univ Perpignan Via Domitia, Montpellier, France.

Emails: olivier.rey@univ-perp.fr; philippe. douchet@univ-perp.fr

Funding information Ministère de l'Enseignement Supérieur et de la Recherche Scientifique; Agence Nationale de Sécurité Sanitaire de l'Alimentation, de l'Environnement et du Travail

\begin{abstract}
The world's parasitic and mutualistic biodiversity is undergoing major upheavals related to modifications in host community structures, changes in interactions between species, and through coextinction events. Trematodes are an important component of this invisible biodiversity, in terms of species richness, but also because of their role in ecosystems functioning and in the emergence of associated diseases. Taken together, these elements point to the need for a better assessment and understanding of the structure and dynamics of trematode diversity. In this context, our aim was to develop an optimized eDNA-based metabarcoding approach to detect trematodes and characterize their communities, most of which associated with aquatic environments. The efficiency of this newly developed tool was first assessed by exhaustive in-silico and in-vitro validation steps. We next assessed the ability of our eDNA-based approach to reconstruct trematode communities compared to a classical trematode monitoring method over four freshwater aquatic ecosystems. Our eDNA-based monitoring tool displayed a high amplification enrichment of trematode DNA, a 100\% detection score for tracking back an in-vitro mock community composed of 28 trematode species, and high genetic resolution, which makes it relevant to discriminate between even phylogenetically close trematode species. Over the four natural ecosystems screened in natura, 33 OTUs were generated from the eDNA-based approach, from which 11 trematode species were identified. In comparison, we identified five trematode species using the classical monitoring method, three of which were also detected by the eDNA-based approach. We believe that this new eDNA-based metabarcoding tool will open new perspectives for fundamental and applied research in community ecology, conservation, and health survey.
\end{abstract}

\section{KEYWORDS}

biodiversity assessment, cryptic diversity, freshwater, metabarcoding, parasites, Trematoda, water-sediment interface 


\section{1 | INTRODUCTION}

Global change including climate changes, land-use, fragmentation, and human-driven international trades deeply modify the spatial distribution of all living organisms worldwide, and largely participate to the ongoing decline of global biodiversity (Ceballos et al., 2015; Pereira et al., 2010; Sage, 2020). In this regard, mutualistic and parasitic organisms are particularly threatened through coextinction, the most common form of biodiversity loss (Carlson et al., 2017; Dunn et al., 2009). In parallel to the massive melting of the overall parasite diversity, we are currently witnessing a significant increase in the spread and abundance of some parasites and consequently the emergence or re-emergence of infectious diseases worldwide (Gottdenker et al., 2014; Jones et al., 2008; White \& Razgour, 2020). As for most organisms, there are likely to be few winners and many losers among parasites during this ongoing massive extinction (Cable et al., 2017; McKinney \& Lockwood, 1999). Together, these elements call for a better assessment and a better comprehension of the structure and dynamics of parasite diversity, a still neglected although certainly the richest and most abundant fraction of overall biodiversity (Poulin \& Morand, 2000).

Digenean trematodes are among the most abundant group of parasitic Platyhelminthes. Estimating the exact number of trematode species is particularly challenging since parasites harbor important cryptic diversity (Poulin, 2011). According to Carlson et al., the number of trematode species could reach up to 44,000 species of which $14 \%$ have been described so far (Carlson et al., 2020). These parasitic worms are ubiquitous over all marine and freshwater ecosystems. They are characterized by a complex life cycle involving some parasitic stages associated with sequential intermediate and definitive obligatory hosts, and often, some free-living aquatic stages that allow the parasite to shift from one sequential host to another (Esch et al., 2002). Trematodes are well known as pathogenic agents responsible for several infectious diseases including bilharziasis, fasciolosis (liver fluke), and food-borne trematodiases, most of which cause sometimes important health issues for humans, livestock, and wild animals (Toledo \& Fried, 2014). Despite their sometimes devastating consequences on human and animal health, trematodes are increasingly recognized as key organisms in ecosystem functioning (Carlson et al., 2020; Dougherty et al., 2016; Marcogliese, 2004). However, trematodes are still generally overlooked. This might be partly explained by the fact that they are very difficult to detect in natural environments, their spatial and temporal distribution is influenced by several biotic and abiotic factors, and they also comprise an important fraction of cryptic species hence complexifying their identification (Poulin, 2011).

Environmental DNA (eDNA) assays have recently become a valuable tool to detect species from environmental samples such as air soil, sediments, or water without seeing or catching them (Beng \& Corlett, 2020; Taberlet et al., 2012). In addition to being less restrictive in terms of sampling effort, eDNA-based methods are generally more efficient than classical monitoring methods to infer species occurrence and thus offer a promising alternative for monitoring cryptic and elusive organisms such as parasites (Bass et al., 2015). So far, targeted eDNA approaches were developed to detect and monitor several trematode species all of which being associated with Human and animal health issues including Schistosoma mansoni (Sengupta et al., 2019), S. haematobium (Alzaylaee et al., 2020), S. japonicum (Worrell et al., 2011), Fasciola hepatica (R. A. Jones et al., 2018), Opisthorchis viverrini (Hashizume et al., 2017), and Ribeiroia ondatrae (Huver et al., 2015). However, in a more general context of biodiversity assessment, no tool so far exists to detect all trematode species and characterize trematode communities in the environment.

To fill this gap, we, here, developed an optimized eDNA-based metabarcoding tool for characterizing and monitoring trematode communities in natura. We first describe a new metabarcode specifically developed for trematodes and provide an exhaustive in-silico and in-vitro validation study regarding its sensibility, specificity, and resolution. We next present a field study to compare the trematode communities characterized by our eDNA-based tool to those identified based on a classical approach combining the shedding of cercaria by mollusks captured in the field and molecular approaches to identify each trematode species. We finally discuss the pros and cons of such eDNA-based approach to characterize trematode communities.

\section{2 | MATERIAL AND METHODS}

\section{1 | In silico primers' design, optimization, and evaluation}

We first built a custom database curated with an exhaustive collection of trematode species' mitogenomes gathered from the GenBank database (i.e., 50 species distributed over 19 phylogenetically distant families (Olson et al., 2003); Table S1). We next ran ecoPrimers version 0.3 (Riaz et al., 2011) using the following parameters: we targeted amplicons with a size comprised between $60 \mathrm{bp}$ and $300 \mathrm{bp}$; we allowed three mismatches between each primer and the primer-binding sequence, we excluded any mismatches at the two final nucleotides at the 3 ' end of the primers and we accounted for the circularized nature of the mitogenome. These parameters are those usually recommended for designing primers in an eDNA context (Taberlet et al., 2018). At the end of this first step, we next filtered the obtained primers so as to target candidate primers that displayed values greater than 0.96 for both, the coverage index (Bc) (i.e., the ratio between the number of amplified taxa and the total taxa number), and the specificity index (Bs) (i.e., the ratio between the number of taxonomically discriminated taxa and the number of amplified taxa).

We next improved the ability of each retained candidate primer to hybridize with DNA sequences from a wide range of trematode species. To do so, we first performed an in silico hybridization test of each primer using the 50 initial trematode mitogenome database as template (Table S1) and Geneious 4.8.2 software (default settings used). We 
then edited the primers manually by incorporating adequate degenerated bases at some specific nucleotidic sites. At each degenerated base incorporation step, the melting temperature of the resulting primers and the potential occurrence of secondary structures (e.g., hairpins, self-dimers and hetero dimers) were checked using IDTDNA's Oligo Analyzer (IDT DNA, 2020). We next selected the final primers based on the best compromise between the maximum number of accepted mismatches (up to 2 per pair of degenerated primers), the primer melting temperature (close to $60^{\circ} \mathrm{C}$ as recommended by Illumina) and the maximum number of nucleotides implicated in secondary structures ( $<1 / 3$ of the primer length maximum).

The quality of the designed primers was next assessed by quantifying their sensitivity (i.e., the percentage of sequences from our trematode database on which the primers hybridize) and their specificity (i.e., their ability to preferentially hybridize to trematode sequences compared to that of other organisms). These two parameters were computed by performing virtual in silico PCR reactions using ecoPCR version 0.2 (Ficetola et al., 2010) and using the custom trematode mitogenome database (Table S1) implemented with mitogenomes from 5624 metazoan species distributed among 26 phyla available from the GenBank nucleotide database (Table S2). We set the ecoPCR parameters to authorize up to 3 mismatches per primer and to select only amplicon lengths between 60bp and $400 \mathrm{bp}$. The number of amplified sequences per phylum and per class of Platyhelminthes was retrieved and the number of mismatches between primers and sequence templates was assessed for each taxonomic group present in the database. Finally, we statistically compared the number of amplified sequences obtained per phylum, and per class of Platyhelminthes, and specifically checked for significant enrichment of the Trematoda Class using a series of Fisher exact tests.

\subsection{In vitro amplification tests}

To assess in vitro, the efficiency of the designed primers to amplify size-expected amplicons in trematodes, we ran PCRs using 40 DNA extracts from 34 trematode species collected during this study (see Section 2.3) and from internal trematode collections (Table S3). PCRs were performed using the GoTaq ${ }^{\circledR}$ G2 Hot Start Polymerase kit of Promega. Each PCR reaction contained Colorless Buffer at $1 \times$, $\mathrm{MgCL} 2$ at $1.5 \mathrm{mM}, \mathrm{dNTPs}$ at $0.2 \mathrm{mM}$, primers at $0.4 \mu \mathrm{M}, 1.25$ units of GoTaq G2 Hot Start, $2 \mu$ of DNA sample, and ultrapure water for a total PCR reaction volume of $25 \mu \mathrm{l}$. The following PCR program was used as follows: An initial denaturation step at $94^{\circ} \mathrm{C}$ for $3^{\prime}$ followed by 40 cycles with a denaturation step at $95^{\circ} \mathrm{C}$ for $30 \mathrm{~s}$, a hybridization step at $54^{\circ} \mathrm{C}$ for $30 \mathrm{~s}$ and an elongation step at $72^{\circ} \mathrm{C}$ for $15 \mathrm{~s}$. We finally performed a final elongation step at $72^{\circ} \mathrm{C}$ for $5^{\prime}$. Ten microliters of the resulting PCR products were migrated on a $2 \%$ agarose gel for $30^{\prime}$ at $135 \mathrm{~V}$ and revealed using a Vilber Infinity 1000 imaging system.

Each individual amplicon from the overall 40 available trematode DNA extracts (Table S3) that displayed a size similar to the theoretical size of the designed metabarcode was sequenced. The forward primer Trem_16S_F1, and the reverse primer Trem_16S_R2 (see Section 3), were used following the same PCR condition as described previously, except that reactions were performed in a final volume of $35 \mu$ l. Additionally, and in order to taxonomically assign each trematode, we also sequenced the positive samples using forward C2'b (5'-GAAAAGTACTTTGRARAGAGA-3') and reverse D2 (5'-TCCGTGTTTCAAGACGGG-3') primers (Huguenin et al., 2019), which amplify part of the 28S D2 domain of rDNA. PCRs followed the same conditions as described previously (performed in a final volume of $35 \mu \mathrm{l}$ ) except that the hybridization step was set at $50^{\circ} \mathrm{C}$ for $30 \mathrm{~s}$ and the elongation step at $72^{\circ} \mathrm{C}$ for $30 \mathrm{~s}$. All amplicons generated were sequenced on an $\mathrm{ABI} 3730 \mathrm{xl}$ sequencer at the GenoScreen platform (Lille, France). For the taxonomic assignment of each trematode, a MEGABLAST analysis was performed with the recovered 28S D2 sequences. The best hits for each sequence (i.e., hits, which presented a similar query cover and a similar identity percentage) were retrieved, and the sequences labeled to the lower taxonomic level were kept.

\section{3 | In natura validation}

We assessed our ability to identify the trematode community in natura using our developed eDNA-based tool from watersediment filtration samples. To this aim we set up a protocol consisting in comparing the trematode community obtained from eDNA samples collected at the water-sediment interfaces to the trematode community characterized based on classical snail emission protocol. The field work was conducted during March and May 2021. We focused on 4 natural sites from Occitanie Region (Southern France) that differ in terms of habitats, and in which the trematode communities were previously at least partially characterized: (1) Salses le château canals (hereafter Salses) consisted in ancient, connected canals used for agriculture yet abandoned since the 1950s'. Water at this site is flowing permanently and three snail species co-occur (Ancylus fluviatilis, Theodoxus fluviatilis, and Potamopyrgus antipodarum). In terms of trematodes, two species were identified including an Opecoelidae species associated with T. fluviatilis and an unidentified trematode producing furcocercariae associated with P. antipodarum. (2) SaintGénis des Fontaines Canals (hereafter Saint-Génis) consisted in a contemporary urban freshwater canal for domestic water use (i.e., garden irrigation). In this system water flows intermittently and only one snail species was identified (Lymnaea stagnalis). The trematode Australapatemon burti was found to be associated to this snail species locally. (3) Villelongue-del-Mont Lake (hereafter Villelongue) consisted in an old gravels exploitation rehabilitated in water plan for recreational fishing. Species found in this lake are mostly invasive species and two snail species were found ( $P$. acuta and Radix sp.). At this site, the trematodes Posthodiplostomum centrarchi, Telorchis attenuata (Moravec \& Vargas-Vázquez, 1998), and a Diplostomidae that we could not identify at the species level 
were previously found associated with $P$. acuta. 4. The Têt River in Néfiach (hereafter Néfiach). This 115-km long river starts its course at an altitude of $2400 \mathrm{~m}$ and flows to the Mediterranean Sea. At this specific site, 3 snail species and one trematode species were found: Radix sp. (associated with a Plagiorchis species), A. fluviatilis, and P. acuta.

At each of these sites, we sampled the water-sediment interface along a 10-m transect against the water flow when discernible (i.e., at Salses, Néfiach and Saint-Génis). The Salses site was sampled twice, in March and May. The water-sediment filtering collection was achieved using disposable water filter capsules with a membrane surface area of $600 \mathrm{~cm}^{2}$ in polyether sulfone and a pore size of $0.45 \mu \mathrm{m}$ (Waterra) and according to recommendations made by Argaly (Argaly; https://www.argaly.com/). Briefly, capsules were connected at the intake end of an electric pump circuit built-up as follow: At the upstream of the capsule, we set up one tube fitted with a check valve (to avoid possible contamination) directly connected to a diaphragm water pump powered by a $12 \mathrm{~V}$ battery. Downstream the pump an output tube was fitted so as to collect the filtered water into a $10 \mathrm{~L}$ graduated collection container hence allowing controlling for the total water volume filtered (Figure S1). Filtrations were carried out until the filters membrane clogged, and the volume filtered at each site was recorded. Moreover, at each site, $8 \mathrm{~L}$ of commercial spring water was filtered following the same protocol as a technical field negative control. Once filtrations completed, capsules were drained from the outlet side, filled with $50 \mathrm{~mL}$ of Longmire buffer solution (Longmire et al., 1997) to preserve the eDNA, closed with end plugs, vigorously agitated, and stored at room temperature until subsequent DNA extraction. During all the sampling process, precautions were taken to avoid any contamination. Operators used disposable sterile gloves and reusable material in close contact with capsules (i.e., tubes fitted with check valves) were decontaminated after each use by successively placing this material in a $10 \%$ bleach bath, in a 70\% ethanol bath and then in a DNA AWAY bath for 1 min each.

Once the eDNA sampling achieved, all snails found were systematically collected at each sampling site manually or by scooping the grass on the water bench using a colander. We set the snail collection time at $1 \mathrm{~h}$ by a unique observer. After their taxonomical identification, snails were individualized on well plates filled with dechlorinated water and left to emit trematodes for $24 \mathrm{~h}$ under a $12 \mathrm{~h}: 12 \mathrm{~h}$ sequential light:dark photoperiod. After measuring trematode prevalence, we then collected and transferred pools of cercariae from the infected snails into $1.5 \mathrm{ml}$ tubes and stored at $-20^{\circ} \mathrm{C}$ until DNA extraction for molecular identification analyses.

\section{4 | Molecular approaches}

All pre-PCR molecular steps were performed under a sterile PCR hood decontaminated before and after each use as follow: the working surface was successively washed using 10\% bleach, $70 \%$ ethanol, a DNA AWAY solution, and exposed to UV light for $20 \mathrm{~min}$.
The reusable materials were decontaminated following the same protocol.

DNA extractions from pools of cercariae collected from the emitting snails were achieved using the Qiagen DNeasy Blood \& Tissue kit. Briefly, we centrifuged the $1.5 \mathrm{ml}$ tubes containing the cercarial pools at $20,000 \mathrm{~g}$ for $10 \mathrm{~min}$. After removing the supernatant, we followed the Tissue protocol as recommended by the supplier. All trematodes obtained from our direct approach were sequenced at the two genetic markers including the barcode developed in this study and the 28S D2 rDNA gene domain (Huguenin et al., 2019).

The longmire solution contained in each eDNA field capsule was split in 3 by pouring the contents of each capsule into three $50 \mathrm{ml}$ Falcon tubes. For the negative controls, the capsule contents were recovered in one $50 \mathrm{ml}$ Falcon tube only. Falcons were centrifugated at $16,000 \mathrm{~g}$ for $20 \mathrm{~min}$ and the supernatant was removed. Next, we collected $1 \mathrm{~g}$ of sediment in the resulting pellet from each falcon tube (triplicates) using a metal spatula cleaned between each subsampling following the decontamination protocol specified above (except for UV exposure). For negative controls, no pellet was observed after centrifugation. In these cases, $500 \mu$ l of Longmire was retained after discarding the supernatant and processed as the other samples. This pre-extraction step led to the processing of 19 samples (i.e., one negative control per site and 3 extraction replicates for each of the five environmental samples). Total environmental genomic DNA was extracted from each triplicate and negative controls using the Qiagen's Dneasy PowerSoil Pro Kit following supplier recommendation.

A total of 50 individual metabarcoding libraries were prepared. These 50 libraries include the triplicates of each filtering capsule (i.e., $3 \times 5=15$ ), four negative controls (one per sampling site) and six positive controls, the PCRs of each of these samples being duplicated (i.e., $25 \times 2=50$ ). The positive controls consisted into two categories of mock communities. The first category of mock community consisted in equimolar pools of 28 DNA extracts (set at a $3.5 \times 10^{-3} \mathrm{ng} / \mu \mathrm{l}$ final concentration) from different trematode species from internal collections (Table S3). These positive controls are useful to detect potential competition bias among trematode sequences during the PCR amplification step. The second mock community consisted in equimolar pools of PCR products independently obtained from the same 28 trematodes species. These controls are useful to detect possible biases during the library preparation and sequencing process.

Individual NGS libraries were prepared following the Illumina two-step PCR protocol, using our developed primers set up with Illumina adapters for the first locus-specific PCR. This first PCR was performed using the GoTaq ${ }^{\circledR}$ G2 Hot Start Polymerase kit of Promega. PCR reactions were performed twice into two independent plates, one in a final volume of $15 \mu \mathrm{l}$ used to check the PCR products through electrophoresis, the other in a final volume of $25 \mu \mathrm{l}$ specifically used for NGS sequencing hence limiting manipulation and possible cross-contamination. Except for the final reaction volume, PCR reactions were performed under the same conditions as described in Section 2.2. 
The resulting PCR products were individually indexed using a second PCR step consisting in eight cycles using the Nextera ${ }^{\mathrm{TM}} \mathrm{XT}$ Index (Illumina, San Diego, USA) following the manufacturer's instructions. Finally, the 50 libraries were normalized using SequalPrep $^{\mathrm{TM}}$ plates (Thermo Fischer Scientific, USA) before pooling. The pooled libraries were then purified following the JetSeq ${ }^{\mathrm{TM}}$ Clean protocol (Bioline, UK), quality checked on a Bioanalyzer High Sensitivity DNA kit (Agilent, USA) and quantified using a Qubit fluorometric quantification (Thermo Fisher Scientific, USA). Paired-end sequencing $(2 \times 250$ cycles) was performed with a MiSeq Reagent Kit v2 on an Illumina $\mathrm{MiSeq}^{\mathrm{TM}}$ instrument at the BioEnvironnement platform (University of Perpignan Via Domitia, France).

\section{5 | Data analysis}

The resulting amplicon sequence dataset was processed using the Find Rapidly OTUs with Galaxy Solution (FROGS) pipeline implemented in Galaxy (Escudié et al., 2018) available from the Genotoul platform (Toulouse, France). (1) The amplicon dataset was first preprocessed by filtering out the sequences so as to keep amplicon sizes from 150 to 400 nucleotides. (2) The sequences kept were next clustered into operational taxonomic units (OTUs) using the swarm algorithm and using denoising and an aggregation distance of three nucleotides (Mahé et al., 2014). (3) The dataset was filtered out for chimeras using VSEARCH (Rognes et al., 2016). (4) Singletons and underrepresented clusters (i.e., clusters whose number of sequences were $<0.1 \%$ of the total number of sequences) were removed. Each OTU was next assigned to a species through a two-step BLAST affiliation procedure. The first BLAST analysis was computed using the standalone blastn program contained in the BLAST + package and a custom trematode sequence database containing a total of 88 sequences including the sequences obtained from the amplicons generated by the in silico ecoPCR (i.e., 50 species; see Section 2.1; Table $\mathrm{S} 1$ ), the sequences generated by the in vitro Sanger sequencing (i.e., 26 species over the 34 species sequenced; see Section 2.2; Table S3), and 12 sequences retrieved from the GenBank database (Table S4). The second BLAST analysis was performed using the online MEGABLAST tool without restricting parameters to achieve affiliation of OTUs that could not be assigned in the first BLAST analysis. The obtained OTUs were filtered for presenting minimal blast coverage of $97 \%$ and a pairwise identity above $97 \%$ with the affiliated sequence. The remaining OTUs were considered as "unassigned". Lastly, we considered that a given OTU was present in a sub sample (i.e., one of the three replicates of a single environmental sample; see Section 2.4 ) if its number of sequences was $>0.1 \%$ of the total number of sequences in each of the two library assigned to this sub sample and if this OTU was present in both libraries (i.e., the two PCR replicates performed on the single subsample; see Section 2.4). This $0.1 \%$ threshold was determined as being the most stringent while allowing the retention of the necessary sequences to detect all the 28 species from the control mock communities.

Finally, we assessed the genetic resolution of the developed metabarcode, that is, to which extent the metabarcode allows us to differentiate between (even close) trematode species. To this aim, we computed pairwise genetic distances between a set of targeted trematode species with various degrees of phylogenetic relatedness. In particular, we combined the 88 sequences contained in our database. All sequences were aligned with T-Coffee on EMBL-EBI (Madeira et al., 2019). Together this set of 88 sequences covered 60 genera within the trematode phylogeny. We next built a neighborjoining phenetic tree based on the percentage of nucleotide differences from the obtained alignment using Jalview version 2.11.1.4 (Waterhouse et al., 2009) for visualization.

\section{3 | RESULTS}

\subsection{In silico primers evaluation and molecular validation}

Our stringent computational searching method resulted in a single pair of primers (Trem_16S_F1 and Trem_16S_R2; Table 1) that produces a metabarcode localized at the $3^{\prime}$ end of the mitochondrial $16 \mathrm{~S}$ rDNA gene and which theoretical size is around 220bp depending on the targeted trematode species.

The in silico PCR performed based on our virtual community of 5674 mitochondrial genomes indicated that these primers were able to amplify an amplicon for $94.3 \%$ of the Platyhelminthe species (i.e., 100 species over the 106 represented species) while, respectively, amplifying only $18.3 \%, 14.3 \%, 5.5 \%, 1.5 \%$ and $0.1 \%$ of the Mollusca, Acanthocephala, Porifera, Arthropoda and Chordata (Figure 1a). Among Platyhelminthes, $100 \%$ of Trematoda, Cestoda and Monogenea were successfully amplified (Figure 1b). The Fisher exact tests indicated that the Platyhelminthes are significantly enriched compared to Mollusca $\left(p\right.$-value $\left.=3^{\mathrm{e}-44}\right)$. Moreover, our set of primers showed no mismatches for $92 \%$ of the trematode species tested, and only 1 mismatch for the remaining $8 \%$ species (Figure S2).

Concerning the in vitro validation step, we obtained a single amplicon of 220 bp as expected from the in silico analysis for all of the 40 DNA extracts from the 34 targeted trematodes species (Table S3).

TABLE 1 Primers designed in this study and their characteristics as determined in IDTDNA's Oligo Analyzer (parameters were set with $0.4 \mu \mathrm{M}$ of primers, $1.5 \mathrm{mM}$ of $\mathrm{Mg}^{2+}$ and $0.2 \mathrm{mM}$ of dNTPs)

\begin{tabular}{|lllll} 
Primer name & Sequence $\left(5^{\prime}-3^{\prime}\right)$ & Average $\operatorname{Tm}\left({ }^{\circ} \mathrm{C}\right)$ & GC content $(\%)$ & Length $\left(\mathrm{bp}^{\prime}\right)$ \\
\hline Trem_16S_F1 & GACGGAAAGACCCCRAGA & 61.8 & 58.3 & 18 \\
\hline Trem-16S_R2 & CRCCGGTYTTAACTCARYTCAT & 62.8 & 45.5 & 22 \\
\hline
\end{tabular}


(a)

$0 \%-10 \%-20 \%-30 \%$

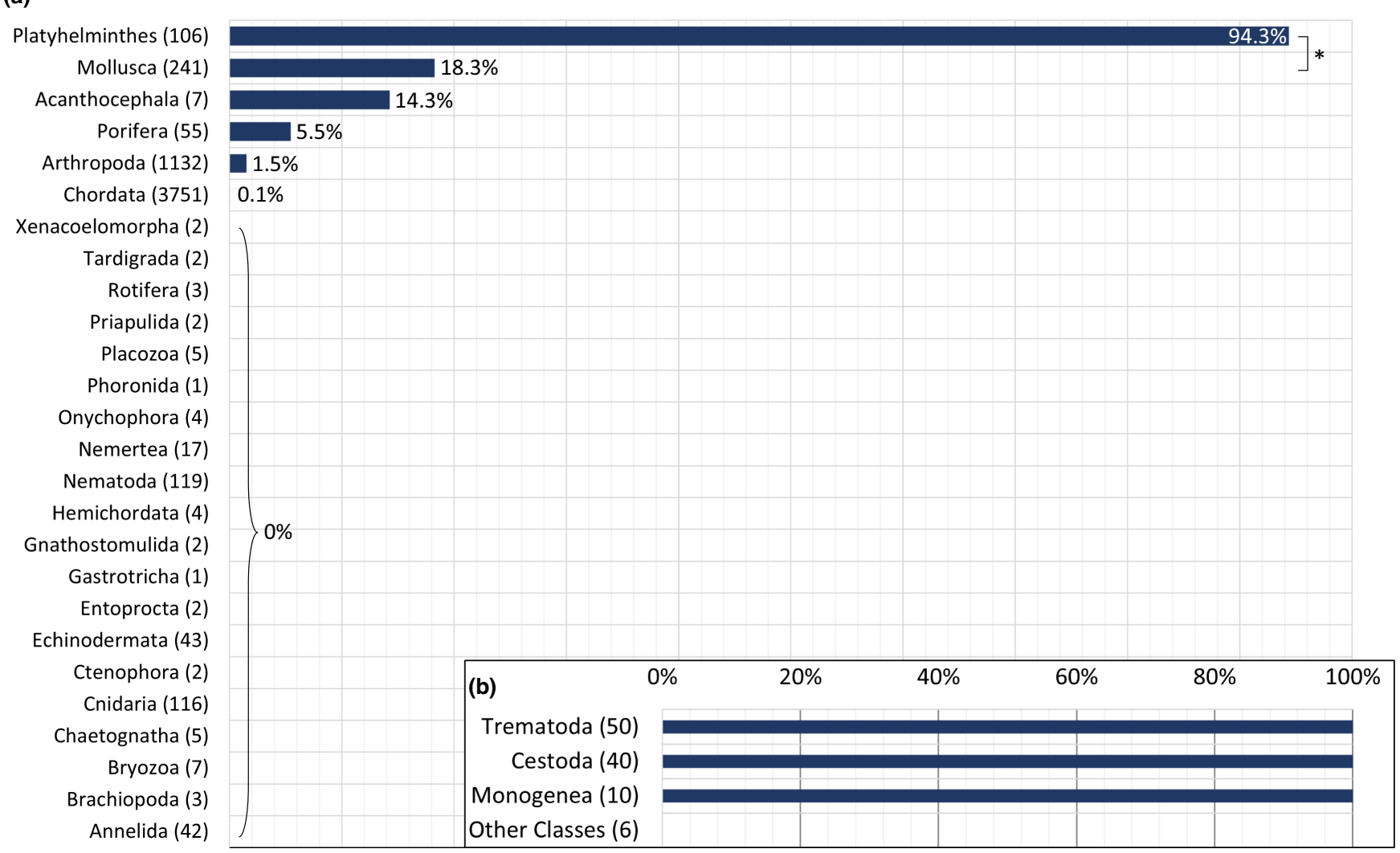

FIGURE 1 Percentage of sequences amplified by in silico PCR with primers developed in this study (a) per phylum and (b) per class of Platyhelminthes when allowing up to 3 mismatches between each primer and the targeted sequences. Numbers in brackets after phyla or class names indicate the number of sequences originally present in the database. *Fisher's exact test $p$-value $<0.001$

\section{2 | Field trematodes survey}

Five trematode species were identified overall from the four sampled sites based on our snail cercarial emission approach (Table 2). Among these 5 species of trematodes, the occurrence of 3 species (i.e., Echinostoma revolutum, Hypoderaeum sp. and Trichobilharzia physellae) was newly recorded at these sites (Table 2). At Salses in March, 382 P. antipodarum were collected but none emitted cercariae. At the same site, in May, 292 P. antipodarum and 56 T. fluviatilis were collected. Among the P. antipodarum, none emitted cercariae, while $8.9 \%$ of the collected T. fluviatilis emitted cotylicercariae of an Opecoelidae species. At Saint-Génis, 191 L. stagnalis were collected of which $2.1 \%$ emitted cercariae of two different species including $E$. revolutum and Hypoderaeum sp. At Villelongue, 131 P. acuta were collected, two of which emitted furcocercariae that were taxonomically assigned to T. physellae and P. centrarchi based on the obtained DNA sequences. Finally, at the Néfiach site, 222 Radix sp. were collected, and none emitted cercariae.

\section{3 | eDNA survey}

A total of 5 capsules were obtained from the four sampled sites. The volumes filtered were $50 \mathrm{~L}$ for each of the two capsules used at Salses in March and May, $20 \mathrm{~L}$ at Saint-Génis, $18 \mathrm{~L}$ at Villelongue and $25 \mathrm{~L}$ at Néfiach.

Overall, a total of $6,426,325$ sequences were obtained from the MiSeq sequencing corresponding to $50(25 \times 2)$ libraries. After pre-processing, $84 \%$ of these sequences were kept (i.e., $5,394,194)$. At this stage, the number of sequences per library ranged from 5 (negative control) to 211,107 with an average of 107,884 sequences per library (Figure S3). After all filtering steps, 4,693,991 sequences, grouped into 53 OTUs, were kept for subsequent analyses.

Regarding the positive controls, 1,885,902 sequences, grouped into 28 OTUs, were retained at the end of the bioinformatic analyses. The number of sequences per library ranged from 90,666 to 199,089 with an average of 157,159 sequences per library (Figure S3). After affiliation the OTUs were consistently assigned to the 28 species initially assembled in the mock communities (Figure 2). In the mock communities consisting in equimolar pools of PCR products, the sequencing resulted in an almost equally distributed number of reads per species as expected (Figure 2a). Conversely, we did observe amplification biases in the mock communities consisting in PCRs from equimolar pools of DNA (Figure $2 b$ ). Importantly, irrespective of the nature of the mock communities, the results obtained across each replicate and each PCR replicate indicated a strong technical replicability (Figure 2). 


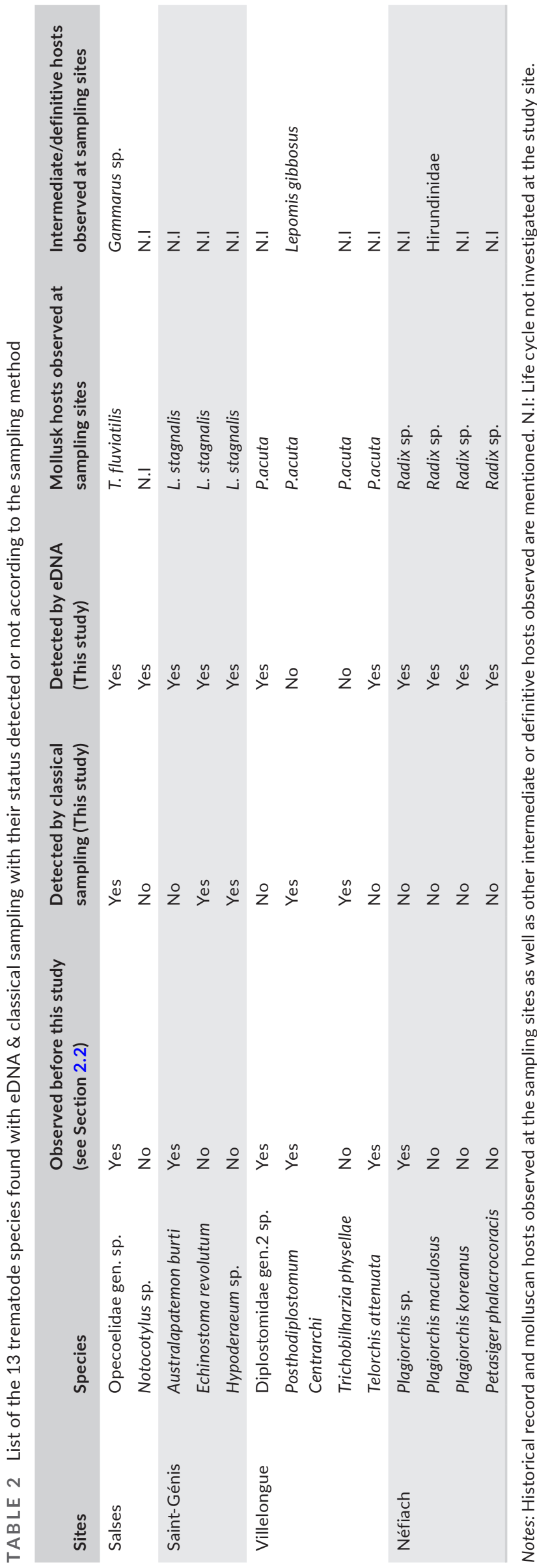

Regarding the libraries from the field eDNA samples and negatives, 2,808,089 sequences were retained at the end of the bioinformatic analyses. The number of reads obtained ranged from 0 (Negative control) to 186,198 . One negative control displayed a non-negligible number of sequences (Salses negative control PCR Duplicate 1: $N=133,203$; PCR Duplicate 2: $N=3$ ) (Figure S3). These sequences were affiliated to $S$. mansoni, one of the Schistosoma species reared and which DNA is frequently manipulated in our laboratory for about 40 years. Sequences of $S$. mansoni and $S$. bovis were also unexpectedly detected in two field subsamples from a single site (i.e., Saint-Génis subsample 1: N1 = 87,614; N2 = 64,125 and subsample 2: $\mathrm{N} 1=83,071 ; \mathrm{N} 2=71,881$ ) where no Schistosoma species may occur. This clearly indicates that despite all precautions taken from eDNA sampling to library preparation, contamination may not be totally prevented.

Excluding sequences of the two OTUs assigned as contamination in field samples and negatives, 2,368,192 sequences were retained at the end of the bioinformatic analyses. Among field samples, the number of sequences per library ranged from 4411 to 182,311 with an average of 78,940 sequences per library (Figure S3). These sequences were grouped into 33 OTUs of which 11 were assigned to trematode species (accounting for $74.9 \%$ of the sequences obtained from field sampling), 1 OTU (1.5\% of the sequences) corresponded to a cestode species and 21 OTUs (23.6\% of the sequences) were unaffiliated according to our filtering parameters. Among the 11 trematode species, the occurrence of 4 species (i.e., Notocotylus sp., Petasiger phalacrocoracis, Plagiorchis maculosus and Plagiorchis koreanus) was newly recorded (i.e., not detected by the field trematodes survey method used in this study and not previously recorded on the study site) overall the four sampled sites (Table 2).

\subsection{Comparison between eDNA monitoring and field trematodes survey}

Overall, 13 trematode species were identified among the four sampling sites when combining the results from our two approaches (i.e., eDNA and field trematodes survey). Eleven trematode species (i.e., $84.6 \%$; 11/13) were identified based on the eDNA-based method, while five trematode species $(38.5 \% ; 5 / 13)$ were identified according to the classical survey (Figure 3 ). Only three trematode species were congruently detected by both methods at the same site (Figure 3). In this regard, eDNA monitoring confirmed the detection obtained by field trematode survey for $60 \%(3 / 5)$ of the detection. The two species $P$. centrarchi and T. physellae detected by the direct approach at the Villelongue site were not detected by eDNA monitoring. Conversely, field trematode survey confirmed the detection obtained by eDNA monitoring for only $27.3 \%$ (3/11) of the detected species (Figure 3).

At the Salses site, two sampling campaigns were achieved in March and May of the same year. At this site, the eDNA method allowed the detection of the Opecoelidae gen. sp. and the Notocotylus sp. only in March. No trematode was detected by this method in 
(a)

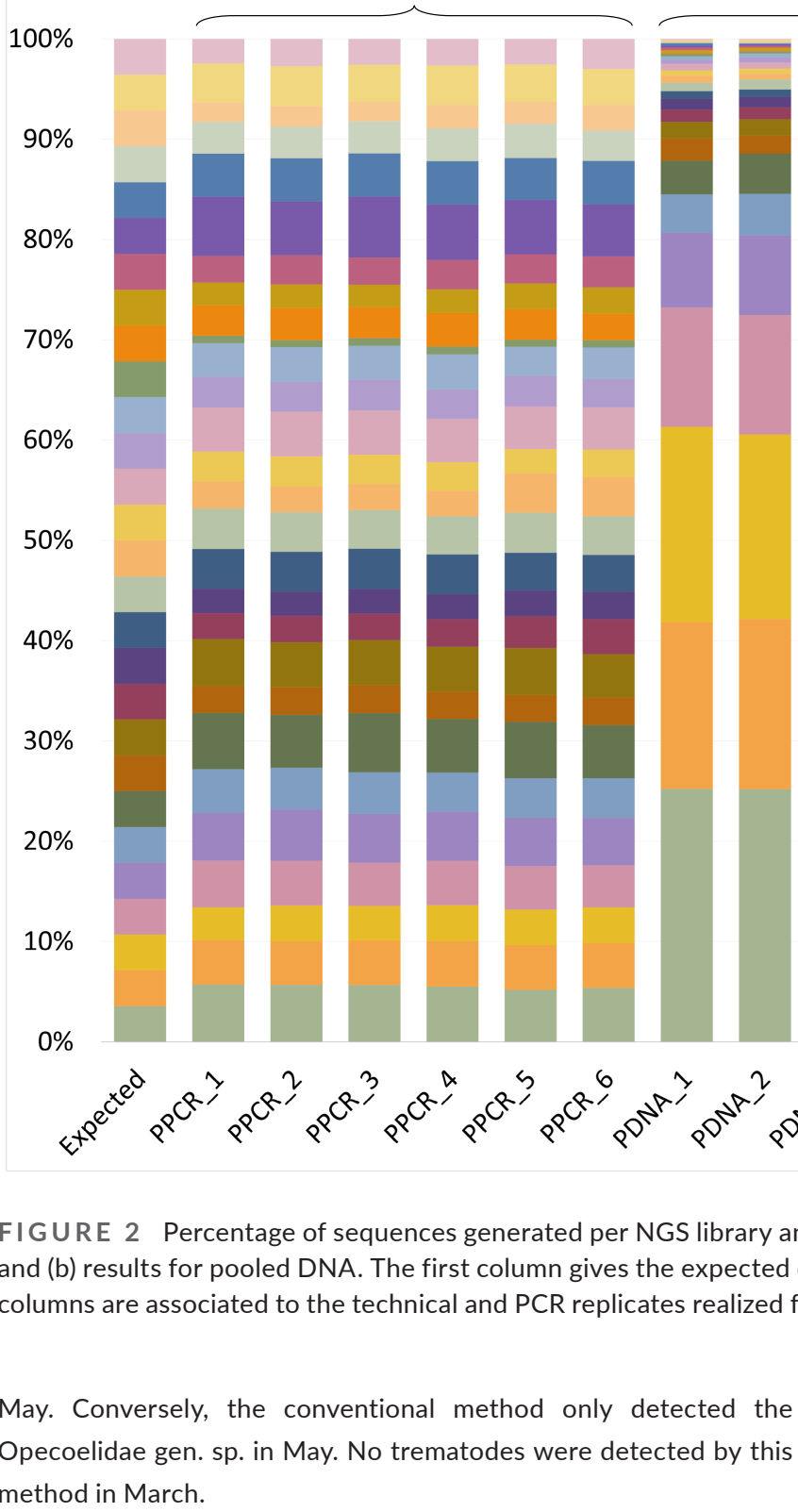

\subsection{Genetic resolution of the developed metabarcode}

In order to assess the resolution of the metabarcode (i.e., the ability of the metabarcode to discriminate trematodes at the species level), the percentage of nucleotide difference in sequence was quantified between each pair of the 88 trematode sequences. The inter-specific variability exceeded $2.81 \%$, value observed between two closely related species (i.e., Diplostomum spathaceum and D. pseudospathaceum) (Figure 4). Furthermore, the phenetic construction from the 88 samples allowed a clustering of the sequences into 9 superfamilies (Figure 4) among the 25 existing superfamilies of digenetic trematodes (Olson et al., 2003; Toledo \& Fried, 2019). (b)

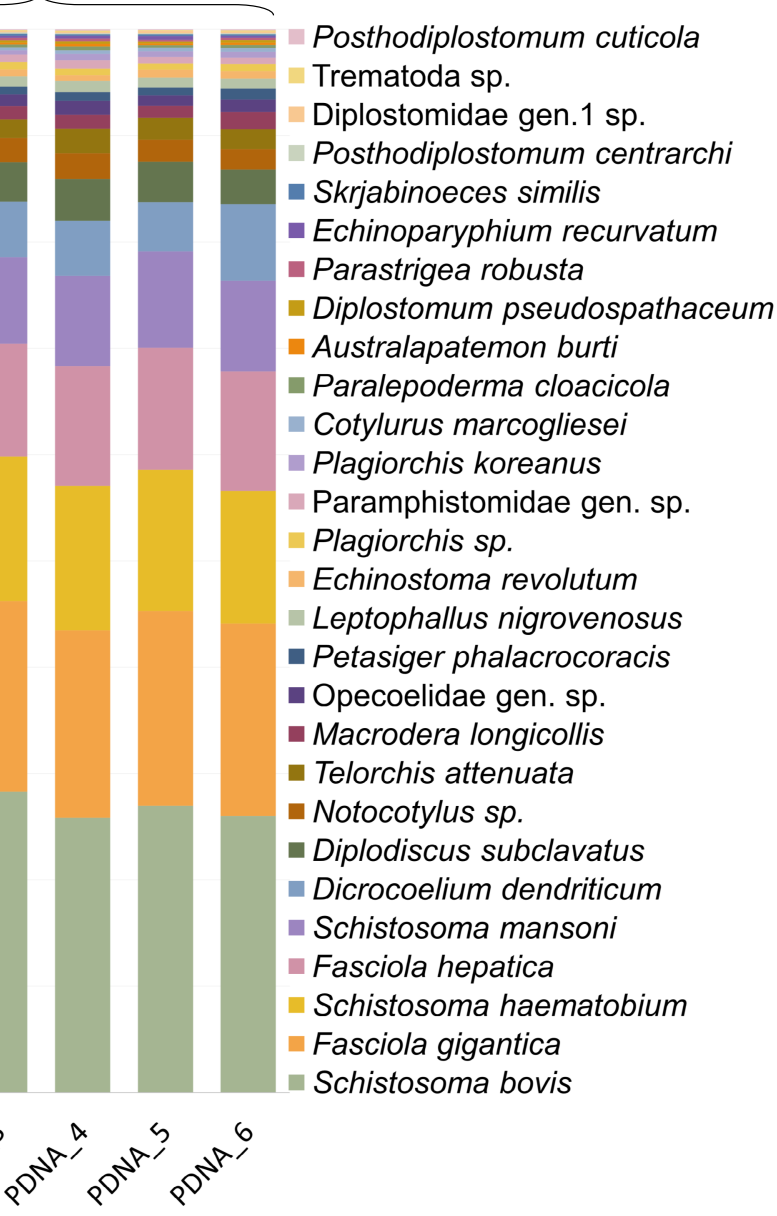




\section{Saint-Génis}

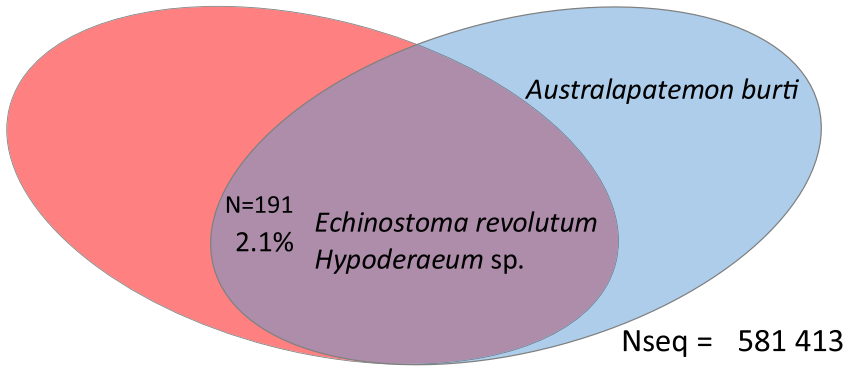

Néfiach

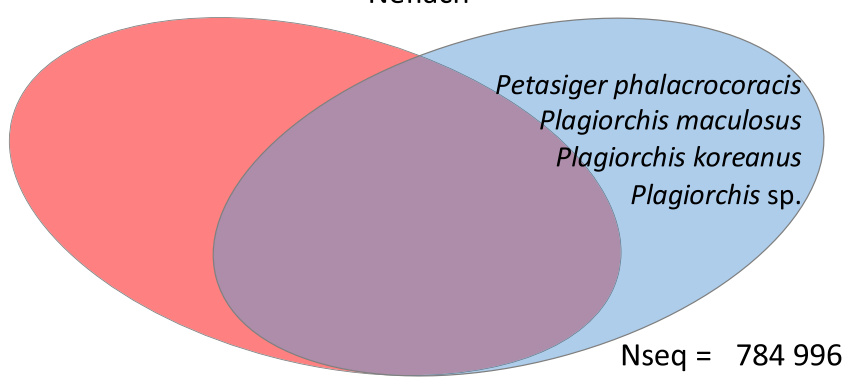

Villelongue

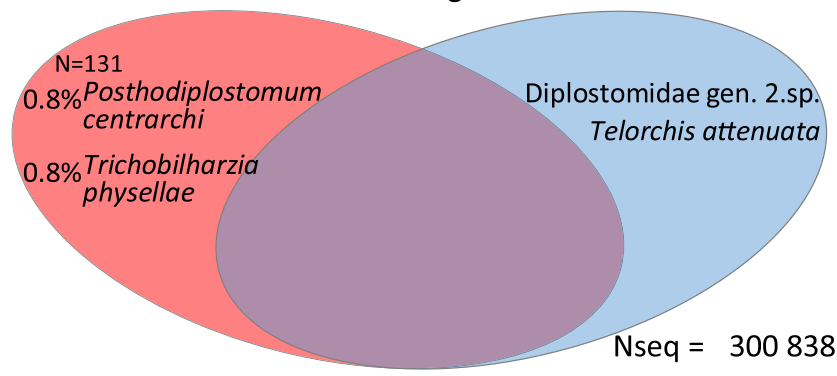

Salses

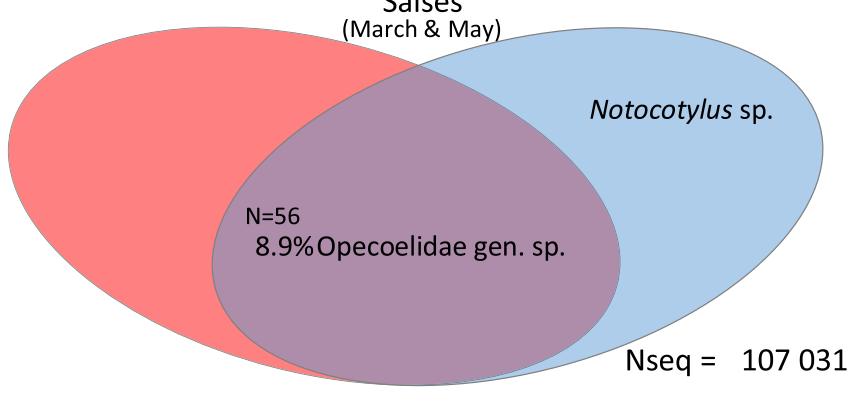

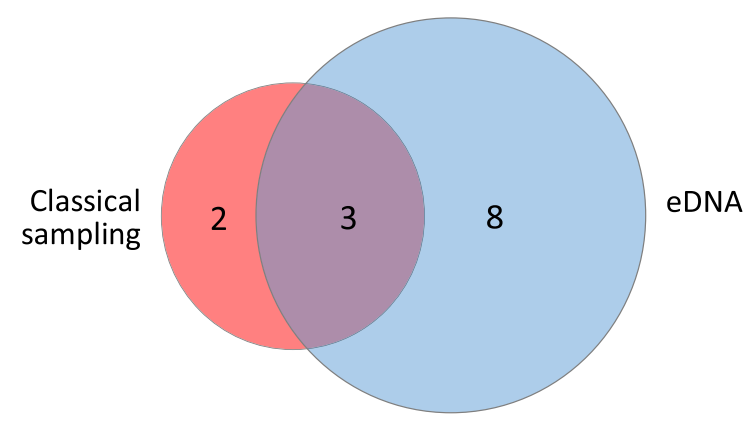

FIGURE 3 Occurrence of trematode species obtained by field trematode survey (in red), eDNA monitoring (in blue), and both at each site and number of species found by each and both methods all sites combined. Percentage on the left of the species name corresponds to the measured prevalence in the mollusk host. $\mathrm{N}$ is the total number of mollusks sampled. Nseq is the total number of sequences successfully affiliated with trematodes at each site

species while the remaining 21 OTUs could not be affiliated to any organisms according to our filtering parameters.

Second, combined with this high specificity, the developed $16 \mathrm{~S}$ rDNA metabarcode is also sensitive (i.e., ability of primers to amplify sequences for as much trematodes as possible) enough to detect all trematode species used in our in silico and in vitro validation steps. In this regard, the developed primers showed no mismatch with $92 \%$ of the trematode DNA sequences available in our database and only 1 mismatch for the remaining $8 \%$ species. We are thus confident that DNA from almost all trematode species could be amplified and detected using this metabarcode, although probably at some varying efficient degrees depending on the number of mismatches with the targeted sequences and the complexity of the DNA sequence community. In fact, our results from the mock community indicate that some species are likely to be more easily detectable than others especially when DNA from different trematode species is present in the same eDNA sample.

Our metabarcode also displays strong genetic resolution (i.e., level of intrinsic genetic diversity assessed over amplicons), which is crucial for identifying organisms to the lowest taxonomic levels. In this respect, the lowest phenetic distance computed in this study is $2.81 \%$ between two closely related Diplostomum species. This is in line with a recent study that confirms that the mitochondrial $16 \mathrm{~s}$ rDNA gene is particularly suitable for trematode species identification (Chan et al., 2021). Finally, although we did not specifically test for the resolution of our metabarcode to discriminate Cestoda and Monogenea, we have clear in silico evidence that this marker could also be useful to characterize communities of Cestoda, Monogenea and probably most Platyhelminthes. Further in silico and in vitro studies are required to assess the performance of this marker (i.e., sensibility and genetic resolution) for other Platyhelminthe species.

\subsection{In natura proof of concept}

According to our sampling design, the eDNA approach appeared more powerful than classical trematode surveys to detect trematodes established locally. This result echoes with those generally 


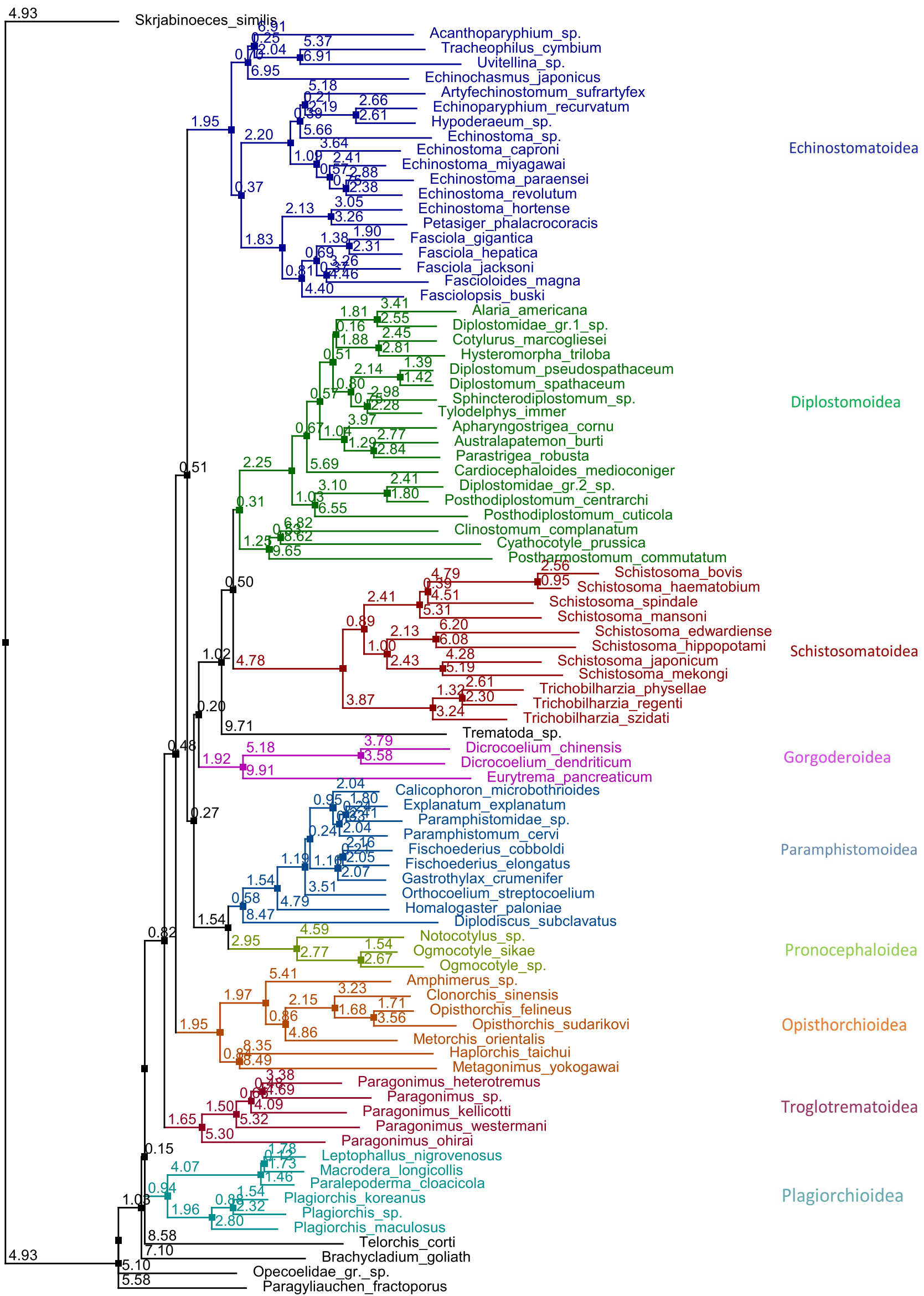

FIGURE 4 Phenogram illustrating the relationships between trematode species based on the percentage of nucleotide differences between the metabarcode sequences. The numbers on each branch indicate the percentage difference in nucleotides between sequences 
obtained in empirical studies that compare classical prospections and eDNA approaches (Deiner et al., 2017; Hänfling et al., 2016; Mulero et al., 2021; Valentini et al., 2016). However, we believe that this particularly holds for trematodes given their complex life cycles and the difficulty to detect them in natura. In fact, trematodes spend more of their life within their definitive hosts, and to a lower extent, within their intermediate hosts. At these parasitic stages, trematodes are thus invisible (Toledo \& Fried, 2019). Trematode free-living stages, including miracidia and cercaria are generally microscopic and particularly difficult to collect and handle from the field for direct identification. Classical approaches to study trematodes in natural environments thus generally rely on the inspection of trematode eggs in vertebrate hosts feces, on the cercarial emissions from snails collected from the field and through inspection of developing trematode stages in dissected snail hosts. Although commonly used to target specific species of trematodes in epidemiological contexts (Akindele et al., 2020; Bärenbold et al., 2017), the former approach is tedious, time-consuming and inconceivable to trace the entire trematode community circulating at a given site. The cercarial emission approach is often jointly used for such prospects but may also be difficult to set up for several reasons. First, prevalence of trematodes in mollusks is generally low in natural populations (Rachprakhon \& Purivirojkul, 2021), which implies the sampling of a huge number of snails to detect only few positive infection. Second, even when snails are infected by trematodes, emission of cercaria generally occurs after a maturing period within the snail (i.e., prepatent period) meaning that not all the infected snails collected during field prospection will emit cercariae. Additionally to this prepatent period, some trematode species are characterized by specific circadian rhythms and will thus be emitted at specific times of the day or night (Théron, 2015). If snails are not monitored for a period long enough, some trematodes can thus be missed. This is how snail dissection is used in addition to cercarial emission to better assess trematode communities and prevalence estimates. Snail dissection is, however, laborious and require specific knowledge in terms of dissection practices. In this study, we based our classical sampling method on the detection and identification of free-living stages of trematodes, which are more likely to be detected and identified by our eDNA-based method as well. Despite our sampling effort and a $24 \mathrm{~h}$ cercarial emission period we only found 5 trematode species using this direct approach while we found more than twice (i.e., $N=11$ ) using our eDNA-based protocol. This huge difference might be explained by our strategy to collect eDNA samples from the water-sediment interface. This sampling scheme allowed collecting not only trematode DNA in its free form or associated to free-living trematode stage swimming in the water column, but also trematode DNA from the sediment either free but also and more likely associated to dead trematode miracidia and cercaria. In fact, most free-living trematodes die before encountering a permissive (intermediate or definitive) host (Morley, 2012) and we might thus expect that most of these free-living dead stages sediment. This strategy also allowed us to obtain true sampling replicates by splitting the sediment obtained from each single capsule into three. In this regard, the results obtained from the triplicates are very similar and this indicates that our approach is highly repeatable. Another non-exclusive hypothesis to explain the difference of communities retrieved from the two approaches, is that since no snail dissection was performed, we could have missed some trematode species and thus underestimate the trematode community richness locally based on our direct approach.

Regarding the 13 trematodes species detected by both approaches in this study, all except T. physellae, were already reported in France or in Europe (Aksenova et al., 2016; Bock \& Janssen, 1987; Demkowska-Kutrzepa et al., 2018; Faltýnková et al., 2008; Kvach et al., 2018; Muñoz-Antolí et al., 2000; Tkach et al., 2000; Toledo \& Esteban, 2016). To our knowledge, this is the first record of the avian schistosome T. physellae in Europe. From an ecological point of view, all trematode species detected by both approaches, except one (i.e., Notocotylus sp.), are known to use at least one co-occurring host species at the target sampling sites. In fact, Notocotylus sp. is the only trematode detected only through eDNA (i.e., not detected by classical method in this study and not previously recorded on the study site) that could not have been identified to the species level. Notocotylus is a genus composed of more than 40 species (Chaisiri et al., 2011) using molluscan hosts of the superorders Caenogastropoda and Heterobranchia (Gonchar et al., 2019) and definitive hosts, which range from waterfowl birds and small mammals (Boyce et al., 2012). Hypotheses about potential host species of this trematode occurring at the sampling site would, therefore, be premature without further investigation. Three other trematode species were detected only by eDNA (i.e., P. phalacrocoracis, P. maculosus and $P$. koreanus). These trematodes, all detected at the Néfiach site, use molluscan hosts of the genus Radix (Bock \& Janssen, 1987; Huguenin et al., 2019; Kudlai et al., 2021), which also occur at this site. Furthermore, the presence of $P$. maculosus is consistent with the presence of swallows (i.e., Hirundinidae; Bock \& Janssen, 1987), observed in high abundance at this site and that act as definitive host for this parasite. In the same vein, cormorants (Phalacrocorax sp.) or bats of the family Vespertilionidae, respectively, definitive hosts of $P$. phalacrocoracis and P. koreanus, although these two vertebrate host species were not observed during sampling, are both present at high abundance in the Occitanie Region. Finally, two trematode species (i.e., P. centrarchi and T. attenuata), detected at Villelongue, are considered as invasive species in Europe (Demkowska-Kutrzepa et al., 2018; Stoyanov et al., 2017). As most recreational lakes, the Villelongue site harbor several exotic introduced vertebrates (e.g., Lepomis gibbosus) and invertebrates (Crayfish) including the mollusk P. acuta. The four trematode species identified in this lake are all associated with $P$. acuta might have been introduced together with their intermediate and definitive hosts. The detection of trematode species associated with these exotic vertebrate and invertebrate species could have been hence expected. Together the detections of all trematode species in this study are thus ecologically congruent.

Among the 13 species of trematodes that were identified using both approaches, two species (i.e., T. physellae and P. centrarchi) were, however, missed by our eDNA-based approach at the Villelongue site. Several non-exclusive hypotheses can be proposed to explain 
such unexpected results. First, these parasites were present at low abundance and below the detection threshold of our eDNA sampling strategy. In accordance with this hypothesis, we observed low prevalence of these two species in mollusks ( $0.8 \%$ for each of them) at the time of the study. Second, additionally to low abundance among snails, free-living stages of these two species might be present at low abundance in the environment due to suboptimal environmental conditions. Indeed, the release of cercariae by mollusks largely depends on abiotic factors such as temperature and light and of the trematode species (Al-Jubury et al., 2020; Koprivnikar \& Poulin, 2009). Third, amplification biases during PCR of the eDNA samples might disfavor the amplification of these two species compared to that of other trematode species. In this respect, one of the two species (i.e., P. centrarchi) was part of the positive mock communities and is among the species for which we obtained the fewest number of sequencing reads. We believe that temporal eDNA sampling replicates at the same targeted sites could help disentangling these three hypotheses. More generally, we argue that temporal studies are also required to better assess the detection dynamics of trematodes from aquatic eDNA samples.

\section{3 | Limitations}

We noticed few drawbacks that require specific attention regarding the eDNA based tool developed in this study. First, although our approach is promising to qualitatively characterize trematode communities, our mock communities indicate that this approach cannot be used to precisely quantify the relative abundance of each trematode species. Indeed amplification biases exist and may result from (1) differences in the number of mismatches between primers and trematode DNA sequences, highlighted for four species in our in silico analysis, (2) different genome sizes or copy numbers of targeted loci between species, as well as differences in organism biomass and (3) factors such as the proportion of GCs in amplicons or the length of amplicons (Krehenwinkel et al., 2017). Second, it is important to note that our proof of concept was conducted in a temperate environment where ecosystems display generally poor biodiversity. The efficiency of this metabarcoding tool to characterize trematode communities in tropical aquatic ecosystems characterized with more diverse organisms' communities remains to be assessed. Importantly, however, given the efficiency of the tool to reconstruct our mock community of 28 species, some of which being tropical, we are confident that it could be applied to tropical environments successfully. Third, we warn on the importance of avoiding any handling of environmental samples in laboratories working on trematodes to prevent contamination. In fact, despite our stringent decontamination protocols and particular care during manipulations, we detected some Schistosoma species in our sequencing libraries, which clearly result a contamination process. These two schistosome species have been manipulated (including living forms, DNA, RNA, cells) in the laboratory for over 40 years. However, because none of the other trematode species detected by eDNA were handled at our laboratory before, their detection is unlikely to result from laboratory contamination. Finally, and probably most importantly, an important current limitation of our tool is the poor number of trematode mitochondrial 16S rDNA gene sequences available in the existing databases. In future, we will improve this aspect by systematically sequencing trematode species for this marker.

\section{4 | Applications}

Despite its limitations, the present eDNA-based tool has several applications both for fundamental and practical studies in ecology and for epidemiological surveillance. Indeed, this eDNA approach could be particularly useful to draw general patterns of the spatial and temporal dynamics of trematode communities in aquatic environments. Moreover, although not specifically assessed in this study, this tool could also be useful to document the lifecycle of some still understudied trematode species. For instance, combined with eDNA approaches on definitive hosts feces or urine (Duval et al., 2021; Huggins et al., 2017), on bulk mollusks or on bulk invertebrates (Ruppert et al., 2019), it might be possible to identify new intermediate or definitive hosts for some trematode species. In an ecological prospective, this metabarcode also constitutes a new tool to detect and monitor invasive species. For instance, we here detected T. attenuata, which presence is potentially problematic because it can cause a possible threat on the native amphibian and reptile species (Cardells et al., 2014; Demkowska-Kutrzepa et al., 2018). Trematodes also display several characteristics that make them promising for developing biodiversity indexes (Huspeni et al., 2004). For instance, in Californian estuaries, Hechinger and Lafferty (2005) found that the diversity of birds is highly correlated with the diversity of trematodes characterized from their snail hosts. In addition, these biodiversity indices could provide additional information to existing ones. Indeed, whereas a traditional bird survey provides a snapshot of bird presence, trematode communities characterization provides a record of the bird community that has visited a site during the lifetime of the infested mollusks, and thus provides an integration through time of bird presence (Hudson et al., 2006). Besides these applications in the field of ecology and biological conservation, this eDNA approach also constitute a promising tool to perform health surveys. Indeed, the detection of some specific trematode species that are pathogenic for humans, livestock, or wildlife in the environment is primordial to identify active transmission sites. Although several specific tools were recently developed to target some of the most pathogenic trematodes (at least for humans) (e.g., Fasciola hepatica; Jones et al., 2018, or Schistosoma mansoni; Sengupta et al., 2019), no tools exist to detect all trematode species. In this regard, two species of trematodes causing human and animal echinostomiasis (i.e., E. revolutum and Hypoderaeum sp.) were detected in the urban irrigation canals at Saint-Génis.

\section{ACKNOWLEDGEMENTS}

This study was funded by the French Agency for Food, Environmental and Occupational Health \& Safety (PNREST 
2019/1/059 Molrisk). SM thanks the Occitania region (MOLRISK) and the EU (FEDER funds). This study is set within the framework of the "Laboratoires d'Excellences (LABEX)" TULIP (ANR-10LABX-41). Finally, the authors warmly thank the BioEnvironnement platform (University of Perpignan) for sequencing and bioinformatics services.

\section{CONFLICT OF INTEREST}

None declared.

\section{DATA AVAILABILITY STATEMENT}

The OTUs table underlying the main results of the study and fastq sequences resulting from sequencing are archived on Dryad https:// doi.org/10.5061/dryad.f7m0cfxxz.

\section{ORCID}

Philippe Douchet (D) https://orcid.org/0000-0002-6689-1710 Stephen Mulero (D) https://orcid.org/0000-0002-0853-0730

\section{REFERENCES}

Akindele, A. A., Adedeji, O. A., Amoo, B., Adekunle, A. A., Adedokun, S. A., Bolaji, O. S., Olowe, O. A., \& Ojurongbe, O. (2020). Epidemiology and burden of Schistosoma haematobium infection among school children in Osun State, Nigeria. American Journal of Biomedical Sciences, 173-182. https://doi.org/10.5099/aj200 300173

Aksenova, O. V., Bespalaya, Y. V., Bolotov, I. N., Kondakov, A. V., \& Sokolova, S. E. (2016). First molecular identification of Australapatemon burti (Miller, 1923) (Trematoda : Digenea: Strigeidae) from an intermediate host Radix labiata (Rossmaessler) (Gastropoda: Lymnaeidae) in Europe. Zootaxa, 4132(4), 588. https://doi.org/10.11646/zoota xa.4132.4.10

Al-Jubury, A., Kania, P., Bygum, A., \& Buchmann, K. (2020). Temperature and light effects on Trichobilharzia szidati cercariae with implications for a risk analysis. Acta Veterinaria Scandinavica, 62(1), 54. https://doi.org/10.1186/s13028-020-00553-z

Alzaylaee, H., Collins, R. A., Rinaldi, G., Shechonge, A., Ngatunga, B., Morgan, E. R., \& Genner, M. J. (2020). Schistosoma species detection by environmental DNA assays in African freshwaters. PLOS Neglected Tropical Diseases, 14(3), e0008129. https://doi. org/10.1371/journal.pntd.0008129

Bärenbold, O., Raso, G., Coulibaly, J. T., N'Goran, E. K., Utzinger, J., \& Vounatsou, P. (2017). Estimating sensitivity of the Kato-Katz technique for the diagnosis of Schistosoma mansoni and hookworm in relation to infection intensity. PLOS Neglected Tropical Diseases, 11(10), e0005953. https://doi.org/10.1371/journ al.pntd.0005953

Bass, D., Stentiford, G. D., Littlewood, D. T. J., \& Hartikainen, H. (2015). Diverse applications of environmental dna methods in parasitology. Trends in Parasitology, 31(10), 499-513. https://doi.org/10.1016/j. pt.2015.06.013

Beng, K. C., \& Corlett, R. T. (2020). Applications of environmental DNA (eDNA) in ecology and conservation: Opportunities, challenges and prospects. Biodiversity and Conservation, 29(7), 2089-2121. https:// doi.org/10.1007/s10531-020-01980-0

Bock, D., \& Janssen, O. (1987). The life-cycle of Plagiorchis maculosus (Rudolphi, 1802) Braun, 1902 (Trematoda : Plagiorchiidae), a parasite of swallows (Hirundinidae). Systematic Parasitology, 9(3), 203212. https://doi.org/10.1007/BF00010855
Boyce, K., Hide, G., Craig, P. S., Harris, P. D., Reynolds, C., Pickles, A., \& Rogan, M. T. (2012). Identification of a new species of digenean Notocotylus malhamensis n. sp. (Digenea : Notocotylidae) from the bank vole (Myodes glareolus) and the field vole (Microtus agrestis). Parasitology, 139(12), 1630-1639. https://doi.org/10.1017/S0031 182012000911

Cable, J., Barber, I., Boag, B., Ellison, A. R., Morgan, E. R., Murray, K., Pascoe, E. L., Sait, S. M., Wilson, A. J., \& Booth, M. (2017). Global change, parasite transmission and disease control: Lessons from ecology. Philosophical Transactions of the Royal Society B: Biological Sciences, 372(1719), 20160088.

Cardells, J., Garijo, M. M., Marín, C., \& Vera, S. (2014). Helminths from the red-eared slider Trachemys scripta elegans (Chelonia : Emydidae) in marshes from the eastern Iberian Peninsula : First report of Telorchis attenuata (Digenea : Telorchiidae). Basic and Applied Herpetology, 28, 153-159. https://doi.org/10.11160/bah.38

Carlson, C. J., Burgio, K. R., Dougherty, E. R., Phillips, A. J., Bueno, V. M., Clements, C. F., Castaldo, G., Dallas, T. A., Cizauskas, C. A., Cumming, G. S., Doña, J., Harris, N. C., Jovani, R., Mironov, S., Muellerklein, O. C., Proctor, H. C., \& Getz, W. M. (2017). Parasite biodiversity faces extinction and redistribution in a changing climate. Science Advances, 3(9), e1602422. https://doi.org/10.1126/ sciadv.1602422

Carlson, C. J., Dallas, T. A., Alexander, L. W., Phelan, A. L., \& Phillips, A. J. (2020). What would it take to describe the global diversity of parasites? Proceedings of the Royal Society B, 287(1939), 20201841. https://doi.org/10.1098/rspb.2020.1841

Carlson, C. J., Hopkins, S., Bell, K. C., Doña, J., Godfrey, S. S., Kwak, M. L., Lafferty, K. D., Moir, M. L., Speer, K. A., Strona, G., Torchin, M., \& Wood, C. L. (2020). A global parasite conservation plan. Biological Conservation, 250, 108596. https://doi.org/10.1016/j. biocon.2020.108596

Ceballos, G., Ehrlich, P. R., Barnosky, A. D., García, A., Pringle, R. M., \& Palmer, T. M. (2015). Accelerated modern human-induced species losses: Entering the sixth mass extinction. Science Advances, 1(5), e1400253. https://doi.org/10.1126/sciadv.1400253

Chaisiri, K., Morand, S., \& Ribas, A. (2011). Notocotylus loeiensis n. sp. (Trematoda : Notocotylidae) from Rattus losea (Rodentia: Muridae) in Thailand. Parasite, 18(1), 35-38. https://doi.org/10.1051/paras ite/2011181035

Chan, A. H. E., Chaisiri, K., Saralamba, S., Morand, S., \& Thaenkham, U. (2021). Assessing the suitability of mitochondrial and nuclear DNA genetic markers for molecular systematics and species identification of helminths. Parasites \& Vectors, 14(1), 233. https://doi. org/10.1186/s13071-021-04737-y

Deiner, K., Bik, H. M., Mächler, E., Seymour, M., Lacoursière-Roussel, A., Altermatt, F., Creer, S., Bista, I., Lodge, D. M., de Vere, N., Pfrender, M. E., \& Bernatchez, L. (2017). Environmental DNA metabarcoding: Transforming how we survey animal and plant communities. Molecular Ecology, 26(21), 5872-5895. https://doi.org/10.1111/ mec.14350

Demkowska-Kutrzepa, M., Studzińska, M., Roczeń-Karczmarz, M., Tomczuk, K., Abbas, Z., \& Różański, P. (2018). A review of the helminths co-introduced with Trachemys scripta elegans - a threat to European native turtle health. Amphibia-Reptilia, 39(2), 177-189. https://doi.org/10.1163/15685381-17000159

Dougherty, E. R., Carlson, C. J., Bueno, V. M., Burgio, K. R., Cizauskas, C. A., Clements, C. F., Seidel, D. P., \& Harris, N. C. (2016). Paradigms for parasite conservation: Parasite Conservation. Conservation Biology, 30(4), 724-733. https://doi.org/10.1111/cobi.12634

Dunn, R. R., Harris, N. C., Colwell, R. K., Koh, L. P., \& Sodhi, N. S. (2009). The sixth mass coextinction: Are most endangered species parasites and mutualists? Proceedings of the Royal Society B: Biological Sciences, 276(1670), 3037-3045. https://doi.org/10.1098/ rspb.2009.0413 
Duval, E., Blanchet, S., Quéméré, E., Jacquin, L., Veyssière, C., Lautraite, A., Garmendia, L., Yotte, A., Parthuisot, N., Côte, J., \& Loot, G. (2021). Urine DNA (uDNA) as a non-lethal method for endoparasite biomonitoring: Development and validation. Environmental DNA. https://doi.org/10.1002/edn3.228

Esch, G. W., Barger, M. A., \& Fellis, K. J. (2002). The Transmission of digenetic trematodes: style, elegance. Complexity. Integrative and Comparative Biology, 42(2), 304-312. https://doi.org/10.1093/ $\mathrm{icb} / 42.2 .304$

Escudié, F., Auer, L., Bernard, M., Mariadassou, M., Cauquil, L., Vidal, K., Maman, S., Hernandez-Raquet, G., Combes, S., \& Pascal, G. (2018). FROGS: Find, rapidly, OTUs with galaxy solution. Bioinformatics, 34(8), 1287-1294. https://doi.org/10.1093/bioin formatics/btx791

Faltýnková, A., Gibson, D. I., \& Kostadinova, A. (2008). A revision of Petasiger Dietz, 1909 (Digenea : Echinostomatidae) and a key to its species. Systematic Parasitology, 71(1), 1-40. https://doi. org/10.1007/s11230-008-9146-6

Ficetola, G., Coissac, E., Zundel, S., Riaz, T., Shehzad, W., Bessière, J., Taberlet, P., \& Pompanon, F. (2010). An In silico approach for the evaluation of DNA barcodes. BMC Genomics, 11(1), 434. https://doi. org/10.1186/1471-2164-11-434

Gonchar, A., Jouet, D., Skírnisson, K., Krupenko, D., \& Galaktionov, K. V. (2019). Transatlantic discovery of Notocotylus atlanticus (Digenea: Notocotylidae) based on life cycle data. Parasitology Research, 118(5), 1445-1456. https://doi.org/10.1007/s00436-019-06297-8

Gottdenker, N. L., Streicker, D. G., Faust, C. L., \& Carroll, C. R. (2014). Anthropogenic land use change and infectious diseases: a review of the evidence. EcoHealth, 11(4), 619-632. https://doi.org/10.1007/ s10393-014-0941-z

Hänfling, B., Handley, L. L., Read, D. S., Hahn, C., Li, J., Nichols, P., Blackman, R. C., Oliver, A., \& Winfield, I. J. (2016). Environmental DNA metabarcoding of lake fish communities reflects long-term data from established survey methods. Molecular Ecology, 25(13), 3101-3119. https://doi.org/10.1111/mec.13660

Hashizume, H., Sato, M., Sato, M. O., Ikeda, S., Yoonuan, T., Sanguankiat, S., Pongvongsa, T., Moji, K., \& Minamoto, T. (2017). Application of environmental DNA analysis for the detection of Opisthorchis viverrini DNA in water samples. Acta Tropica, 169, 1-7. https://doi. org/10.1016/j.actatropica.2017.01.008

Hechinger, R. F., \& Lafferty, K. D. (2005). Host diversity begets parasite diversity: Bird final hosts and trematodes in snail intermediate hosts. Proceedings of the Royal Society B: Biological Sciences, 272(1567), 1059-1066. https://doi.org/10.1098/rspb.2005.3070

Hudson, P. J., Dobson, A. P., \& Lafferty, K. D. (2006). Is a healthy ecosystem one that is rich in parasites? Trends in Ecology \& Evolution, 21(7), 381-385. https://doi.org/10.1016/j.tree.2006.04.007

Huggins, L. G., Michaels, C. J., Cruickshank, S. M., Preziosi, R. F., \& Else, K. J. (2017). A novel copro-diagnostic molecular method for qualitative detection and identification of parasitic nematodes in amphibians and reptiles. PLoS One, 12(9), e0185151. https://doi. org/10.1371/journal.pone.0185151

Huguenin, A., Depaquit, J., Villena, I., \& Ferté, H. (2019). MALDI-TOF mass spectrometry: A new tool for rapid identification of cercariae (Trematoda, Digenea). Parasite, 26, 11. https://doi.org/10.1051/ parasite/2019011

Huspeni, T. C., Hechinger, R. F., \& Lafferty, K. D. (2004). Trematode parasites as estuarine indicators: opportunities, applications, and comparisons with conventional community approaches. In S.A. Bortone (Ed.), Estuarine Indicators (1st Edition, p. 18). CRC Press.

Huver, J. R., Koprivnikar, J., Johnson, P. T. J., \& Whyard, S. (2015). Development and application of an eDNA method to detect and quantify a pathogenic parasite in aquatic ecosystems. Ecological Applications, 25(4), 991-1002. https://doi.org/10.1890/14-1530.1

IDT DNA. (2020). IDT Integrated DNA technologies. https://eu.idtdna. com/calc/analyzer
Jones, K. E., Patel, N. G., Levy, M. A., Storeygard, A., Balk, D., Gittleman, J. L., \& Daszak, P. (2008). Global trends in emerging infectious diseases. Nature, 451(7181), 990-993. https://doi.org/10.1038/natur e06536

Jones, R. A., Brophy, P. M., Davis, C. N., Davies, T. E., Emberson, H., Rees Stevens, P., \& Williams, H. W. (2018). Detection of Galba truncatula, Fasciola hepatica and Calicophoron daubneyi environmental DNA within water sources on pasture land, a future tool for fluke control? Parasites \& Vectors, 11(1), 342. https://doi.org/10.1186/s1307 1-018-2928-z

Koprivnikar, J., \& Poulin, R. (2009). Interspecific and intraspecific variation in Cercariae release. Journal of Parasitology, 95(1), 14-19. https://doi.org/10.1645/GE-1582.1

Krehenwinkel, H., Wolf, M., Lim, J. Y., Rominger, A. J., Simison, W. B., \& Gillespie, R. G. (2017). Estimating and mitigating amplification bias in qualitative and quantitative arthropod metabarcoding. Scientific Reports, 7(1), 17668. https://doi.org/10.1038/s41598-017-17333-x

Kudlai, O., Pantoja, C., O'Dwyer, K., Jouet, D., Skírnisson, K., \& Faltýnková, A. (2021). Diversity of Plagiorchis (Trematoda: Digenea) in high latitudes: Species composition and snail host spectrum revealed by integrative taxonomy. Journal of Zoological Systematics and Evolutionary Research, 59(5), 937-962. https://doi.org/10.1111/ jzs.12469

Kvach, Y., Matvienko, N., Bryjová, A., \& Ondračková, M. (2018). Aquaculture as a possible vector in the spread of Posthodiplostomum centrarchi (Hoffman, 1958) (Digenea : Diplostomidae) in Europe. Biolnvasions Records, 7(4), 427-432. https://doi.org/10.3391/ bir.2018.7.4.12

Longmire, J. L., Maltbie, M., \& Baker, R. J. (1997). Use of" lysis buffer" in DNA isolation and its implication for museum collections. Museum of Texas Tech University.

Madeira, F., Park, Y. M., Lee, J., Buso, N., Gur, T., Madhusoodanan, N., Basutkar, P., Tivey, A. R. N., Potter, S. C., Finn, R. D., \& Lopez, R. (2019). The EMBL-EBI search and sequence analysis tools APIs in 2019. Nucleic Acids Research, 47(W1), W636-W641. https://doi. org/10.1093/nar/gkz268

Mahé, F., Rognes, T., Quince, C., de Vargas, C., \& Dunthorn, M. (2014). Swarm: Robust and fast clustering method for amplicon-based studies. PeerJ, 2, e593. https://doi.org/10.7717/peerj.593

Marcogliese, D. J. (2004). Parasites: Small players with crucial roles in the ecological theater. EcoHealth, 1(2), 151-164. https://doi. org/10.1007/s10393-004-0028-3

McKinney, M. L., \& Lockwood, J. L. (1999). Biotic homogenization: A few winners replacing many losers in the next mass extinction. Trends in Ecology \& Evolution, 14(11), 450-453. https://doi.org/10.1016/ S0169-5347(99)01679-1

Moravec, F., \& Vargas-Vázquez, J. (1998). Some endohelminths from the freshwater turtle Trachemys scripta from Yucatan, Mexico. Journal of Natural History, 32(3), 455-468. https://doi.org/10.1080/00222 939800770241

Morley, N. J. (2012). Cercariae (Platyhelminthes : Trematoda) as neglected components of zooplankton communities in freshwater habitats. Hydrobiologia, 691(1), 7-19. https://doi.org/10.1007/s1075 0-012-1029-9

Mulero, S., Toulza, E., Loisier, A., Zimmerman, M., Allienne, J.-F., Foata, J., Quilichini, Y., Pointier, J.-P., Rey, O., \& Boissier, J. (2021). Malacological survey in a bottle of water: A comparative study between manual sampling and environmental DNA metabarcoding approaches. Global Ecology and Conservation, 25, e01428. https:// doi.org/10.1016/j.gecco.2020.e01428

Muñoz-Antolí, C., Toledo, R., \& Esteban, J. G. (2000). The life cycle and transmission dynamics of the larval stages of Hypoderaeum conoideum. Journal of Helminthology, 74(2), 165-172. https://doi. org/10.1017/S0022149X00000238

Olson, P. D., Cribb, T. H., Tkach, V. V., Bray, R. A., \& Littlewood, D. T. J. (2003). Phylogeny and classification of the Digenea 
(Platyhelminthes: Trematoda). International Journal for Parasitology, 33(7), 733-755. https://doi.org/10.1016/S0020-7519(03)00049-3

Pereira, H. M., Leadley, P. W., Proença, V., Alkemade, R., Scharlemann, J. P. W., Fernandez-Manjarrés, J. F., Araújo, M. B., Balvanera, P., Biggs, R., Cheung, W. W. L., Chini, L., Cooper, H. D., Gilman, E. L., Guénette, S., Hurtt, G. C., Huntington, H. P., Mace, G. M., Oberdorff, T., Revenga, C., ... Walpole, M. (2010). Scenarios for global biodiversity in the 21st Century. Science, 330(6010), 1496-1501. https:// doi.org/10.1126/science.1196624

Poulin, R. (2011). Uneven distribution of cryptic diversity among higher taxa of parasitic worms. Biology Letters, 7(2), 241-244. https://doi. org/10.1098/rsbl.2010.0640

Poulin, R., \& Morand, S. (2000). The diversity of parasites. The Quarterly Review of Biology, 75(3), 277-293. https://doi.org/10.1086/393500

Rachprakhon, P., \& Purivirojkul, W. (2021). Very low prevalence of Opisthorchis viverrini s.l. Cercariae in Bithynia siamensis siamensis snails from the canal network system in the Bangkok Metropolitan Region, Thailand. Parasite, 28, 2. https://doi.org/10.1051/paras ite/2020072

Riaz, T., Shehzad, W., Viari, A., Pompanon, F., Taberlet, P., \& Coissac, E. (2011). ecoPrimers: Inference of new DNA barcode markers from whole genome sequence analysis. Nucleic Acids Research, 39(21), e145. https://doi.org/10.1093/nar/gkr732

Rognes, T., Flouri, T., Nichols, B., Quince, C., \& Mahé, F. (2016). VSEARCH: A versatile open source tool for metagenomics. PeerJ, 4, e2584. https://doi.org/10.7717/peerj.2584

Ruppert, K. M., Kline, R. J., \& Rahman, M. S. (2019). Past, present, and future perspectives of environmental DNA (eDNA) metabarcoding: A systematic review in methods, monitoring, and applications of global eDNA. Global Ecology and Conservation, 17, e00547. https:// doi.org/10.1016/j.gecco.2019.e00547

Sage, R. F. (2020). Global change biology: A primer. Global Change Biology, 26(1), 3-30.

Sengupta, M. E., Hellström, M., Kariuki, H. C., Olsen, A., Thomsen, P. F., Mejer, H., Willerslev, E., Mwanje, M. T., Madsen, H., Kristensen, T. K., Stensgaard, A.-S., \& Vennervald, B. J. (2019). Environmental DNA for improved detection and environmental surveillance of schistosomiasis. Proceedings of the National Academy of Sciences, 116(18), 8931-8940. https://doi.org/10.1073/pnas.1815046116

Stoyanov, B., Georgieva, S., Pankov, P., Kudlai, O., Kostadinova, A., \& Georgiev, B. B. (2017). Morphology and molecules reveal the alien Posthodiplostomum centrarchi Hoffman, 1958 as the third species of Posthodiplostomum Dubois, 1936 (Digenea : Diplostomidae) in Europe. Systematic Parasitology, 94(1), 1-20. https://doi. org/10.1007/s11230-016-9680-6

Taberlet, P., Bonin, A., Coissac, E., \& Zinger, L. (2018). Environmental DNA: For biodiversity research and monitoring. Oxford University Press.

Taberlet, P., Coissac, E., Hajibabaei, M., \& Rieseberg, L. H. (2012). Environmental DNA. Molecular Ecology, 21(8), 1789-1793. https:// doi.org/10.1111/j.1365-294X.2012.05542.x

Taberlet, P., Coissac, E., Pompanon, F., Brochmann, C., \& Willerslev, E. (2012). Towards next-generation biodiversity assessment using DNA metabarcoding. Molecular Ecology, 21(8), 2045-2050. https:// doi.org/10.1111/j.1365-294X.2012.05470.x

Théron, A. (2015). Chronobiology of trematode cercarial emergence: From data recovery to epidemiological, ecological and evolutionary implications. Advances in Parasitology, Vol. 88 (pp. 123-164). Elsevier. https://doi.org/10.1016/bs.apar.2015.02.003

Tkach, V. V., Pawlowski, J., \& Sharpilo, V. P. (2000). Molecular and morphological differentiation between species of the Plagiorchis vespertilionis group (Digenea, Plagiorchiidae) occurring in European bats, with a re-description of P. vespertilionis (Müller, 1780). Systematic Parasitology, 47(1), 9-22. https://doi.org/10.1023/A:10063 58524045

Toledo, R., \& Esteban, J. G. (2016). An update on human echinostomiasis. Transactions of the Royal Society of Tropical Medicine and Hygiene, 110(1), 37-45. https://doi.org/10.1093/trstmh/trv099

Toledo, R., \& Fried, B. (2014). Digenetic trematodes, Vol. 480. Springer.

Toledo, R., \& Fried, B. (2019). Digenetic Trematodes (2nd edn). Springer. https://doi.org/10.1007/978-3-030-18616-6

Valentini, A., Taberlet, P., Miaud, C., Civade, R., Herder, J., Thomsen, P. F., Bellemain, E., Besnard, A., Coissac, E., Boyer, F., Gaboriaud, C., Jean, P., Poulet, N., Roset, N., Copp, G. H., Geniez, P., Pont, D., Argillier, C., Baudoin, J.-M., ... Dejean, T. (2016). Next-generation monitoring of aquatic biodiversity using environmental DNA metabarcoding. Molecular Ecology, 25(4), 929-942. https://doi.org/10.1111/ mec.13428

Waterhouse, A. M., Procter, J. B., Martin, D. M. A., Clamp, M., \& Barton, G. J. (2009). Jalview Version 2-A multiple sequence alignment editor and analysis workbench. Bioinformatics (Oxford, England), 25(9), 1189-1191. https://doi.org/10.1093/bioinformatics/btp033

White, R. J., \& Razgour, O. (2020). Emerging zoonotic diseases originating in mammals: A systematic review of effects of anthropogenic land-use change. Mammal Review, 50(4), 336-352. https://doi. org/10.1111/mam.12201

Worrell, C., Xiao, N., Vidal, J. E., Chen, L., Zhong, B., \& Remais, J. (2011). Field detection of Schistosoma japonicum Cercariae in environmental water samples by quantitative PCR. Applied and Environmental Microbiology, 77(6), 2192-2195. https://doi.org/10.1128/ AEM.01561-10

\section{SUPPORTING INFORMATION}

Additional supporting information may be found in the online version of the article at the publisher's website.

How to cite this article: Douchet, P., Boissier, J., Mulero, S., Ferté, H., Doberva, M., Allienne, J.-F., Toulza, E., Bethune, K., \& Rey, O. (2022). Make visible the invisible: Optimized development of an environmental DNA metabarcoding tool for the characterization of trematode parasitic communities. Environmental DNA, 4, 627-641. https://doi.org/10.1002/ edn3.273 